ARTICLE

https://doi.org/10.1038/s41467-019-13907-7

\title{
Acidity enhancement through synergy of penta- and tetra-coordinated aluminum species in amorphous silica networks
}

\author{
Zichun Wang ${ }^{1,2}$, Tong Li ${ }^{3}$, Yijiao Jiang (10 2, Olivier Lafon ${ }^{4,5}$, Zongwen Liu', Julien Trébosc ${ }^{6}$, Alfons Baiker (1) ${ }^{7}$, \\ Jean-Paul Amoureux ${ }^{4,8,9 *} \&$ Jun Huang (iD) ${ }^{1 \star}$
}

Amorphous silica-aluminas (ASAs) are widely used in acid-catalyzed $\mathrm{C}-\mathrm{H}$ activation reactions and biomass conversions in large scale, which can be promoted by increasing the strength of surface Brønsted acid sites (BAS). Here, we demonstrate the first observation on a synergistic effect caused by two neighboring Al centers interacting with the same silanol group in flame-made ASAs with high Al content. The two close Al centers decrease the electron density on the silanol oxygen and thereby enhance its acidity, which is comparable to that of dealuminated zeolites, while ASAs with small or moderate Al contents provide mainly moderate acidity, much lower than that of zeolites. The ASAs with enhanced acidity exhibit outstanding performances in $\mathrm{C}-\mathrm{H}$ bond activation of benzene and glucose dehydration to 5-hydroxymethylfurfural, simultaneously with an excellent calcination stability and resistance to leaching, and they offer an interesting potential for a wide range of acid and multifunctional catalysis.

\footnotetext{
${ }^{1}$ Laboratory for Catalysis Engineering, School of Chemical and Biomolecular Engineering \& Sydney Nano Institute, The University of Sydney, Sydney, NSW 2006, Australia. ${ }^{2}$ Department of Engineering, Macquarie University, Sydney, NSW 2109, Australia. ${ }^{3}$ Institute for Materials \& ZGH, Ruhr-Universität Bochum, 44801 Bochum, Germany. ${ }^{4}$ Univ. Lille, CNRS, UMR 8181, UCCS-Unité de Catalyse et de Chimie du Solide, F-59000 Lille, France. ${ }^{5}$ Institut Universitaire de France, Centrale Lille, ENSCL, Villeneuve-d'Ascq, France. ${ }^{6}$ Univ. Lille, CNRS, INRA, Centrale Lille, ENSCL, Univ. Artois, FR 2638 - IMEC Institut Michel-Eugène Chevreul, F-59000 Lille, France. ${ }^{7}$ Institute for Chemical and Bioengineering, Department of Chemistry and Applied Biosciences, ETH, Zürich, Hönggerberg, $\mathrm{HCl} \mathrm{CH}-8093$, Switzerland. ${ }^{8}$ Bruker Biospin, 34, rue de l'industrie, 67166 Wissembourg, France. ${ }^{9}$ Riken NMR Science and Development Division, Yokohama 230-0045 Kanagawa, Japan. *email: jean-paul.amoureux@univ-lille.fr; jun.huang@sydney.edu.au
} 
S ilica-alumina materials, particularly crystalline zeolites and amorphous silica-aluminas (ASAs), are among the most popular solid acids that have been widely commercialized as efficient and environmentally friendly catalysts in the petrochemical industry ${ }^{1}$, and in bio-refinery ${ }^{2}$. These materials can provide Brønsted acid sites (BAS) with tunable density and strength, which facilitates the optimization of the surface acidity to promote a series of important industrial chemical reactions, through the formation of surface complexes or transition states by proton transfer from BAS to reactants ${ }^{3-6}$, such as to initialize $\mathrm{C}-\mathrm{H}$ activation for hydrocarbon conversions ${ }^{7-12}$. Zeolites with strong Brønsted acidity, are of increasing importance in various sustainable processes, in the fields of biomass conversion, $\mathrm{CO}_{2}$ capture and conversion, air-pollution remediation, and water purification $^{13}$. For instance, zeolites can efficiently catalyze the redox disproportionative conversion of biomass-derived sugars into $a$-hydroxy acids ${ }^{14}$, and they are more active than ASA catalysts, albeit the latter facilitate improved molecular diffusion in the porous network ${ }^{15}$. The lower performance of ASA in many catalytic applications is widely attributed to their moderate Brønsted acidity ${ }^{1}$, which fostered recent works on the discovery of ASAs with increased Brønsted acidity ${ }^{5}$, aiming at expanding their applications in a broad range of fields.

The formation of BAS in silica-aluminas is based on aluminum centers distributed in the silica framework or network ${ }^{6,16-20}$, as (i) a tetra-coordinated aluminum species $\left(\mathrm{Al}^{\mathrm{IV}}\right)$, replacing a $\mathrm{Si}^{4+}$ atom in the zeolite framework, can introduce a negatively charged framework oxygen to be balanced by a proton, resulting in bridging $\mathrm{OH}$ groups ${ }^{6,17,18}$, and (ii) the interaction between $\mathrm{Al}^{\mathrm{IV}}$ atoms and neighboring silanols in the silica network can provide acidic $\mathrm{OH}$ groups, acting as BAS in ASA ${ }^{5,21-24}$. In crystalline zeolites, it is well accepted that increasing the $\mathrm{Si} / \mathrm{Al}$ ratio can enhance the BAS strength by increasing the overall electronegativity ${ }^{25}$. However, the amount of BAS (e.g. bridging SiOHAl groups) is then significantly reduced, owing to the fewer $\mathrm{Al}$ sites in the framework. Alternatively, the introduction of extra-framework cations, such as $\mathrm{Al}^{3+}$ and $\mathrm{La}^{3+}$, via dealumination or ion exchange can significantly improve the BAS strength due to a synergistic effect between Lewis acid sites (LAS) and nearby BAS ${ }^{4,17}$. Those solid acids have been widely applied in gas-phase cracking, such as fluid catalytic cracking processes ${ }^{26}$. However, extra-framework cations can easily leach out from solid acids during the liquid-phase reactions ${ }^{27}$. Additionally, the synergy between two nearby Al sites in the zeolite framework is impossible due to the absence of Al-OAl linkage based on Löwenstein's rule ${ }^{28}$.

Enhancing the BAS strength in ASAs still remains a significant challenge. Although a surface bridging SiOHAl model has been proposed for the formation of BAS on $\mathrm{ASA}^{21,29}$, the strength of the BAS on ASA is generally lower than that on crystalline zeolites $^{1}$, since the amorphous structure of ASAs weakens the Al-O bonds $(2.94-4.43 \AA)^{24}$, compared to those in the crystalline zeolite framework $(1.88-2.0 \AA)^{30}$. Two models have been proposed to account for BAS generation in ASA: (i) a flexible coordination between the $\mathrm{Al}$ atom and the neighboring silanol oxygen atom $^{5,23}$, and (ii) a pseudo-bridging silanol (PBS) with a nearby $\mathrm{Al}$ atom $24,31,32$. In both models, it was proposed that a Lewis acidic Al center interacts with a nearby silanol group, withdrawing electron density from the hydroxyl $\mathrm{O}$ atom to enhance the acid strength of the hydroxyl proton. Notably, these models mainly account for the formation of moderate BAS. Nevertheless, the presence of an additional $\mathrm{Al}$ species in the vicinity of the $\mathrm{SiOH}$ site may further enhance the acid strength of ASA via a synergistic effect, which has not yet been evidenced to the best of our knowledge.

In this work, the synergy between $\mathrm{Al}$ species in the ASA network has been studied using solid-state NMR spectroscopy and atom probe tomography (APT). The ${ }^{27} \mathrm{Al}$ double-quantum single-quantum (DQ-SQ) through-space homonuclear correlation (D-HOMCOR) NMR experiments allow us to probe ${ }^{27} \mathrm{Al}-{ }^{27} \mathrm{Al}$ proximities by applying recoupling sequences that restore the dipolar interaction between neighboring ${ }^{27} \mathrm{Al}$ spins ${ }^{33-36}$. Unlike for crystallized materials, the investigation of the location and distribution of $\mathrm{Al}$ atoms is impossible in ASAs by routine characterization methods, such as X-ray diffraction (XRD) and highresolution transmission electron microscopy (HRTEM), due to their amorphous structure. Atom probe tomography (APT) can provide quantitative three-dimensional (3D) information on elemental distributions in catalyst nanoparticles at the atomic scale ${ }^{37,38}$. It has recently been employed with sub-nanometerscale resolution on zeolite-based catalysts to establish their structure-composition-property relationships ${ }^{39-43}$. Here, we apply APT for the same purpose in $\mathrm{ASAs}^{44-47}$. The combined investigations of APT on Al distribution and ${ }^{27} \mathrm{Al}$ and ${ }^{1} \mathrm{H}$ DQ-SQ NMR experiments reveal, for the first time, the existence of a synergy between Al species in the ASA network. This synergy can significantly enhance the acid strength of ASA, as demonstrated by the H/D exchange with deuterated benzene. The beneficial effect of the enhanced acidity is demonstrated by an example of the liquid-phase catalytic dehydration of glucose to 5-hydroxymethylfurfural, which is an important building block in the production of various valuable chemicals, such as liquid alkanes, biofuels, and furan derivatives ${ }^{48}$.

\section{Results}

Local structure of SA/10. The ASA materials were prepared by flame spray pyrolysis as described in Supplementary Methods and they are designated as $\mathrm{SA} / \mathrm{x}$, where $\mathrm{x}=10$ or 50 represents the percentage of $\mathrm{Al}$ atoms with respect to the total amount of $\mathrm{Al}$ and $\mathrm{Si}$ atoms in the precursor. APT has been applied to show the distribution of Al within the SA/10 as shown in Supplementary Fig. 1 and Supplementary Movie 1 in the Supplementary Information. The tomographic reconstruction qualitatively shows a homogeneous distribution of $\mathrm{Al}, \mathrm{Si}$ and $\mathrm{O}$ (Supplementary Fig. $1 \mathrm{~b}, \mathrm{c}, \mathrm{d}$ ), where each sphere represents the $3 \mathrm{D}$ position of an individual atom. In agreement with recent energy-dispersive Xray atom mapping investigations ${ }^{49}$, the APT reveals a homogeneous dispersion of $\mathrm{Al}$ species in the silica network, similar to that observed in well-developed crystalline zeolites ${ }^{42,43}$. Due to the lack of evidence for the existence of zeolite-like bridging $\mathrm{OH}$ groups in ASA, Al atoms in SA/10 can be expected either bridged to $\mathrm{SiO}(\mathrm{SiOAl})$ or located nearby the silanol groups $(\mathrm{SiO}(\mathrm{H}) \cdots \mathrm{Al})$, as reported in literature ${ }^{16,21}$.

Supplementary Fig. 2a displays the single-pulse $1 \mathrm{D}{ }^{27} \mathrm{Al}$ MAS spectrum of SA/10. It exhibits three peaks at 50, 30, and $4 \mathrm{ppm}$, assigned to tetra- $\left(\mathrm{Al}^{\mathrm{IV}}\right)$, penta- $\left(\mathrm{Al}^{\mathrm{V}}\right)$ and hexa- $\left(\mathrm{Al}^{\mathrm{VI}}\right)$ coordinated $\mathrm{Al}$ sites, respectively ${ }^{16,50}$. In the DQ-SQ 2D spectra, as shown in Fig. 1, autocorrelation diagonal peaks resonating at the frequencies $(2 v, v)$ along the indirect and direct dimensions, respectively, indicate the proximities between nuclei with identical isotropic shifts, $v$, whereas the cross-peak pairs resonating at frequencies $\left(v_{\mathrm{a}}+v_{\mathrm{b}}, v_{\mathrm{a}}\right)$ and $\left(v_{\mathrm{a}}+v_{\mathrm{b}}, v_{\mathrm{b}}\right)$ specify proximities between nuclei resonating at distinct frequencies, $v_{\mathrm{a}}$ and $v_{\mathrm{b}}$, in the $1 \mathrm{D}$ spectra. The ${ }^{27} \mathrm{Al} \mathrm{DQ}-\mathrm{SQ} 2 \mathrm{D}$ spectrum (Fig. 1a) exhibits a weak diagonal peak at $(60,30) \mathrm{ppm}$, which indicates proximities between $\mathrm{Al}^{\mathrm{V}}$ sites in SA/10. No other obvious ${ }^{27} \mathrm{Al}$ correlation signal could be detected, which was confirmed by the ${ }^{27} \mathrm{Al}$ slices that were extracted at the corresponding shifts of these correlation signals (Supplementary Fig. 2e-i). The ${ }^{1} \mathrm{H}$ MAS spectrum of SA/10 shown in Supplementary Fig. 2b exhibits a single peak resonating at $1.9 \mathrm{ppm}$, which is ascribed to the silanol protons. The ${ }^{1} \mathrm{H}$ DQ-SQ $2 \mathrm{D}$ spectrum shows a single strong 
a

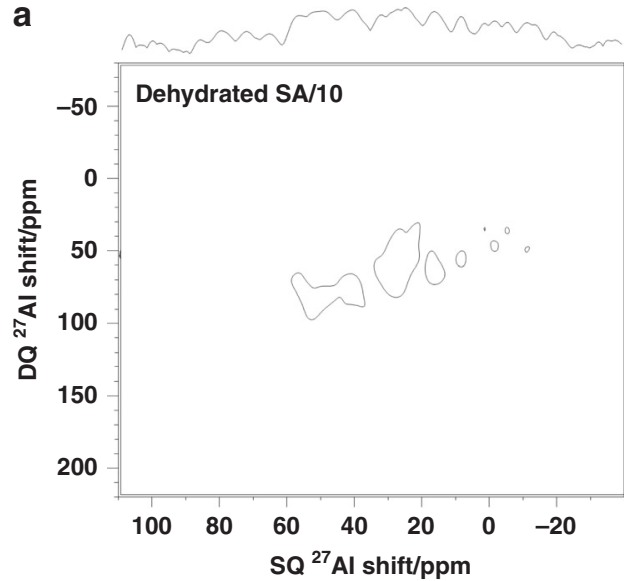

C

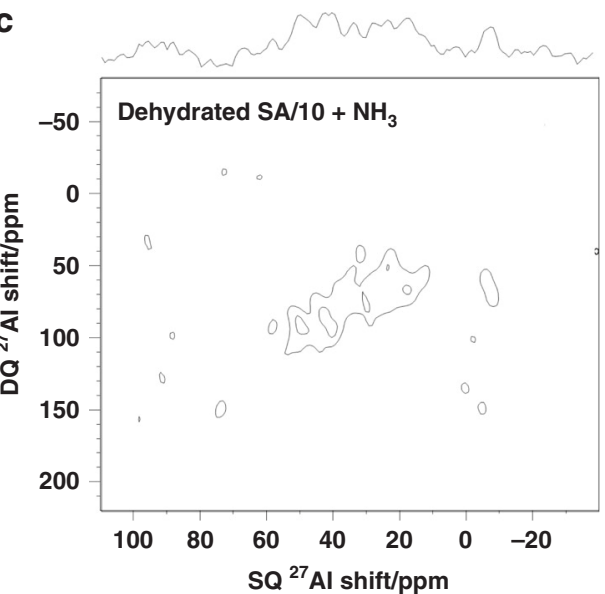

b
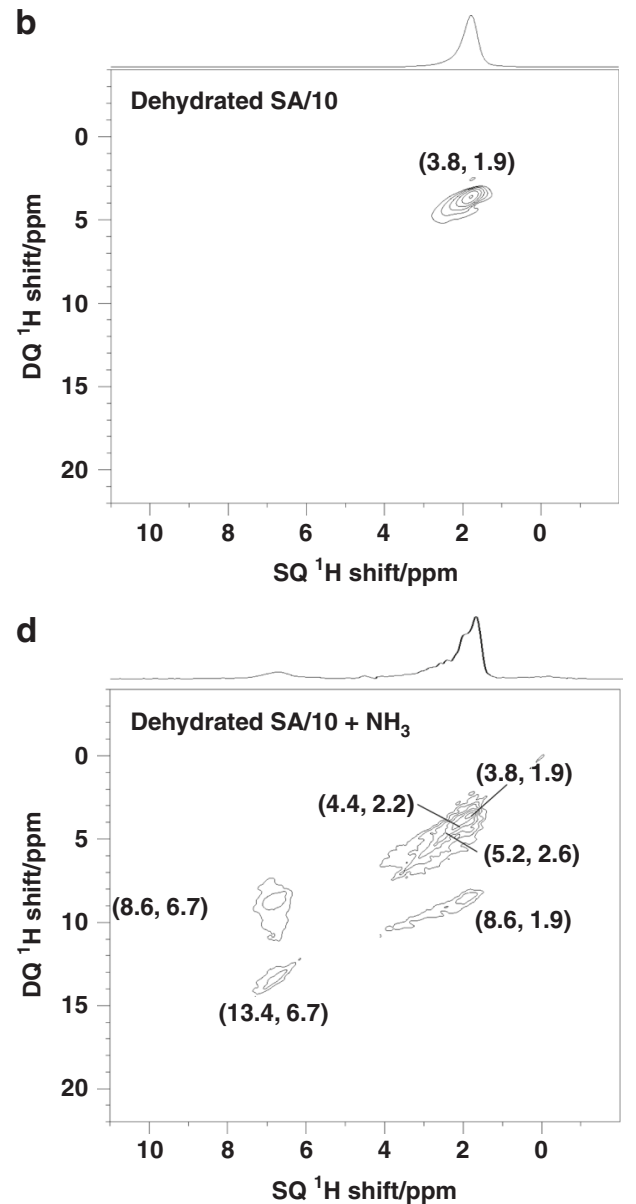

Fig. 1 DQ-SQ D-HOMCOR 2D NMR spectra of SA/10. The spectra of subfigures $\mathbf{a}, \mathbf{c}$ and $\mathbf{b}, \mathbf{d}$ are for ${ }^{27} \mathrm{Al}$ and ${ }^{1} \mathrm{H}$ NMR spectra, respectively, acquired at $18.8 \mathrm{~T}$ with a MAS frequency of $\nu_{\mathrm{R}}=20 \mathrm{kHz}$. The spectra of subfigures $\mathbf{a}$ and $\mathbf{b}$ were acquired for $\mathrm{SA} / 10$ dehydrated at $723 \mathrm{~K}$ for $12 \mathrm{~h}$ under vacuum, whereas the spectra of subfigures $\mathbf{c}$ and $\mathbf{d}$ were dehydrated and loaded with ammonia, and then evacuated at $393 \mathrm{~K}$ for $1 \mathrm{~h}$ to remove the weakly physisorbed molecules.

signal at $(3.8,1.9)$ ppm (Fig. 1b). This peak indicates the spatial proximity of many silanol groups on the surface.

The presence of BAS has been further confirmed by the adsorption of a basic molecular probe, ammonia. The ${ }^{1} \mathrm{H}$ spectrum of SA/10 loaded with ammonia (see Supplementary Fig. 2d) exhibits a peak at $\delta_{1 \mathrm{H}}=6.7 \mathrm{ppm}$, which is ascribed to ammonium ions ${ }^{6}$. The presence of an auto-correlation peak at $(13.4,6.7) \mathrm{ppm}$ in the ${ }^{1} \mathrm{H}$ DQ-SQ spectrum of Fig. $1 \mathrm{~d}$ indicates that the ammonium protons are dipolar coupled and hence, do not exhibit isotropic motion in the sample. The cross-peaks at $(8.6,1.9)$ and $(8.6,6.7) \mathrm{ppm}$ in the same spectrum demonstrate mainly that some ammonia ions stay adsorbed near the $\mathrm{SiOH}$ groups. The peak at $\delta_{1 \mathrm{H}}=2.6 \mathrm{ppm}$ is assigned to ammonia adsorbed at LAS ${ }^{51-54}$. The autocorrelation peak at $(5.2,2.6) \mathrm{ppm}$ in Fig. 1d indicates that the protons of adsorbed ammonia are dipolar coupled and hence that these molecules do not exhibit isotropic motions. Conversely, the ${ }^{27} \mathrm{Al} 1 \mathrm{D}$ (Supplementary Fig. 2c) and 2D D-HOMCOR (Fig. 1c) spectra are not significantly modified by the adsorption of ammonia. In particular, we only detect a weak $\mathrm{Al}^{\mathrm{V}}$ diagonal peak in the $2 \mathrm{D}$ $D$-HOMCOR spectrum, and no other correlation signal could be detected as observed with dehydrated SA/10 (Fig. 1a).

The ${ }^{13} \mathrm{C}$ NMR signal of SA/10 loaded with $\mathrm{CH}_{3}{ }^{13} \mathrm{COCH}_{3}$ probe molecule resonates at $\delta_{13 \mathrm{C}}=213 \mathrm{ppm}^{5}$. This value is similar to those observed in most ASA samples ${ }^{22}$, but is much smaller than that of zeolite H-ZSM-5 $\left(\delta_{13 \mathrm{C}}=223 \mathrm{ppm}\right)^{55}$. This chemical shift $\delta_{13 \mathrm{C}}$ value is commonly utilized to evaluate the strength of acid sites in solid acids, e.g., a larger $\delta_{13 \mathrm{C}}$ value indicates a higher acid strength ${ }^{6}$. Hence, the BAS of SA/10 exhibits a moderate acidity. These sites have been described as $\mathrm{SiOH}$ groups in the proximity of one $\mathrm{Al}^{\mathrm{IV}}$ or $\mathrm{Al}^{\mathrm{V}}$ site $\mathrm{e}^{16}$.

Local structure of SA/50. The APT reconstructions of SA/50 in Fig. 2, Supplementary Fig. 3, and Supplementary Movie 2 show the $3 \mathrm{D}$ distributions of $\mathrm{Al}, \mathrm{Si}$ and $\mathrm{O}$ species. Visually, the $\mathrm{Si}$ and $\mathrm{O}$ species are homogeneously distributed, similarly to those observed in Supplementary Fig. 1 for SA/10, however, the Al atoms are distributed rather heterogeneously. The comparison of these APT reconstructions with those in SA/10 (Supplementary Fig. 1) shows a higher Al density in SA/50. Additionally, a radial distribution function (RDF) 56,57 was calculated to further evaluate the clustering tendency of Al (Supplementary Note 1). The $\mathrm{RDF}$ of $\mathrm{Al}$ in SA/10 shows no significant positive or negative correlation, which is in a good agreement with the random $\mathrm{Al}$ distribution in the silica network without significant clustering in $\mathrm{SA} / 10$. The RDF of $\mathrm{Al}$ in SA/50 has a high positive correlation indicating that more and more $\mathrm{Al}$ species are close to each other. Indeed, at high $\mathrm{Al}$ concentration, more $\mathrm{Al}$ species in the network lead to shorter average $\mathrm{Al}-\mathrm{Al}$ distance in SA/50 than in SA/10. 
Hence, more than one $\mathrm{Al}$ center can be expected in the proximity of a $\mathrm{SiOH}$ group in SA/50.

The ${ }^{27} \mathrm{Al}$ 1D NMR spectrum of SA/50 (Supplementary Fig. 4a) indicates the presence of $\mathrm{Al}^{\mathrm{IV}}, \mathrm{Al}^{\mathrm{V}}$ and $\mathrm{Al}^{\mathrm{VI}}$ species in that sample. Moreover, the relative amount of $\mathrm{Al}^{\mathrm{V}}$ sites is higher in SA/50 than in SA/10 (compare Supplementary Figs. 2a and 4a). Various correlation peaks were detected in the ${ }^{27} \mathrm{Al}$ DQ-SQ 2D spectrum of dehydrated $\mathrm{SA} / 50$ as shown in Fig. 3a, providing information about the proximities between the different $\mathrm{Al}$ sites. The most intense peak is the diagonal one of $\mathrm{Al}^{\mathrm{V}}$ site at $(60,30)$ ppm (Fig. 3d). When normalized by the number of transients and the Al molar fraction, the intensity of that peak is 3-fold higher for SA/50 than for SA/10 in the spectrum of Fig. 1a. This higher intensity indicates a shorter average distance between the closest

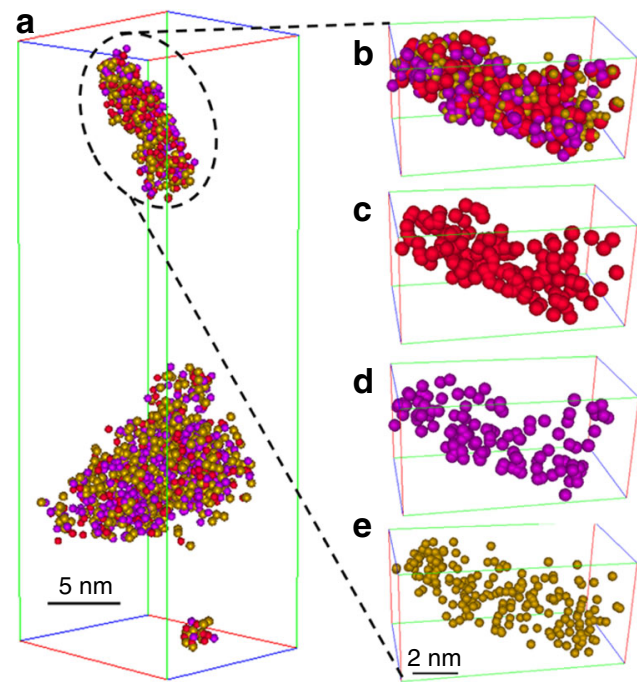

Fig. 2 3D-APT reconstruction of two isolated SA/50 nanoparticles. a All atoms. $\mathbf{b}$ Enlargement of the top SA/50 nanoparticle in a, showing only $\mathbf{c} \mathrm{Al}, \mathbf{d} \mathrm{Si}$ and $\mathbf{e} \mathrm{O}$. The 3D-APT reconstruction of the bottom nanoparticle of a is shown in Supplementary Fig. 3.
$\mathrm{Al}^{\mathrm{V}}$ sites in $\mathrm{SA} / 50$ than in $\mathrm{SA} / 10$, in line with the APT data (Supplementary Note 1). The pair of intense cross-peaks at (85, $55)$ and $(85,30) \mathrm{ppm}$ also indicates that a significant amount of $\mathrm{Al}^{\mathrm{V}}$ species $\left(\delta_{27 \mathrm{Al}}=30 \mathrm{ppm}\right)$ is close to $\mathrm{Al}^{\mathrm{IV}}$ ones $\left(\delta_{27 \mathrm{Al}}=55\right.$ ppm) (Fig. 3e). An $\mathrm{Al}^{\mathrm{V}}-\mathrm{Al} \mathrm{VI}^{\mathrm{VI}}$ correlation is also detected at $(34,4)$ and $(34,30)$ ppm (Fig. 3c). The weak cross-peaks at $(59,55)$ and $(59,4) \mathrm{ppm}$ detected in Fig. $3 \mathrm{~d}$ also indicate the proximity between $\mathrm{Al}^{\mathrm{IV}}$ and $\mathrm{Al}^{\mathrm{VI}}$ species. The weak diagonal signals at $(8,4)$ or $(110,55) \mathrm{ppm}$ point to proximities between two $\mathrm{Al}^{\mathrm{VI}}$ or two $\mathrm{Al}^{\mathrm{IV}}$ sites, respectively. However, owing to the low density of $\mathrm{Al}^{\mathrm{VI}}$ and $\mathrm{Al}^{\mathrm{IV}}$ species, these peaks are very weak, as shown in the corresponding slices of Fig. 3b, f, respectively.

The ${ }^{1} \mathrm{H}$ 1D NMR spectrum of dehydrated SA/50 (Supplementary Fig. 4b) is dominated by the signal of $\mathrm{SiOH}$ groups resonating at $1.9 \mathrm{ppm}$. The shoulder at $1.1 \mathrm{ppm}$ is assigned to non-acidic terminal $\mathrm{Al}^{\mathrm{VI}} \mathrm{OH}$ protons ${ }^{16}$. The ${ }^{1} \mathrm{H}$ DQ-SQ spectrum in Supplementary Note 2 exhibits an intense autocorrelation peak at $(3.8,1.9) \mathrm{ppm}$, indicating close proximity between silanol protons. As mentioned above, the RDF data in Supplementary Note 1 indicates that almost all network $\mathrm{Si}$ atoms are close to $\mathrm{Al}$ ones. Furthermore, it has been shown for SA/50 using ${ }^{1} \mathrm{H}_{-}{ }^{27} \mathrm{Al}$ through-space correlation experiments at $18.8 \mathrm{~T}$ that the silanol protons are mostly close to $\mathrm{Al}^{\mathrm{IV}}$ and $\mathrm{Al}^{\mathrm{V}}$ sites ${ }^{16}$. Hence, the intense autocorrelation peak for silanol protons in the ${ }^{1} \mathrm{H}$ DQ-SQ $2 \mathrm{D}$ spectrum is consistent with the intense $\mathrm{Al}^{\mathrm{IV}}-\mathrm{Al}^{\mathrm{V}}$ and $\mathrm{Al}^{\mathrm{V}}-\mathrm{Al}^{\mathrm{V}}$ correlations detected in the ${ }^{27} \mathrm{Al}$ DQ-SQ 2D spectrum (Fig. 3d, e).

As already observed for SA/10, the loading of SA/50 with ammonia leads to the appearance of a signal of ammonium protons at $6.7 \mathrm{ppm}$ in the ${ }^{1} \mathrm{H} 1 \mathrm{D}$ NMR spectrum. The relative intensity of this signal with respect to that of silanol is higher for SA/50 than for SA/10, which indicates the increased amount of BAS in SA/50 in agreement with previous studies ${ }^{5}$. The ${ }^{1} \mathrm{H}$ DQSQ 2D spectrum of SA/50 loaded with ammonia is shown in Supplementary Note 2 . The significant increase of the broad autocorrelation signal at $(2.6,5.2) \mathrm{ppm}$ with increasing $\mathrm{Al} / \mathrm{Si}$ ratio from $1 / 9$ to $5 / 5$ (compare Fig. $1 \mathrm{~d}$ and Supplementary Note 2) allows assigning it to ammonia adsorbed on $\mathrm{LAS}^{51-54}$. Such assignment is supported by previously reported $2 \mathrm{D}{ }^{27} \mathrm{Al}-{ }^{1} \mathrm{H}$ through-space correlations of SA/10 and SA/50 loaded with ammonia ${ }^{16}$. In those spectra, the ${ }^{1} \mathrm{H}$ signal resonating at $2.6 \mathrm{ppm}$

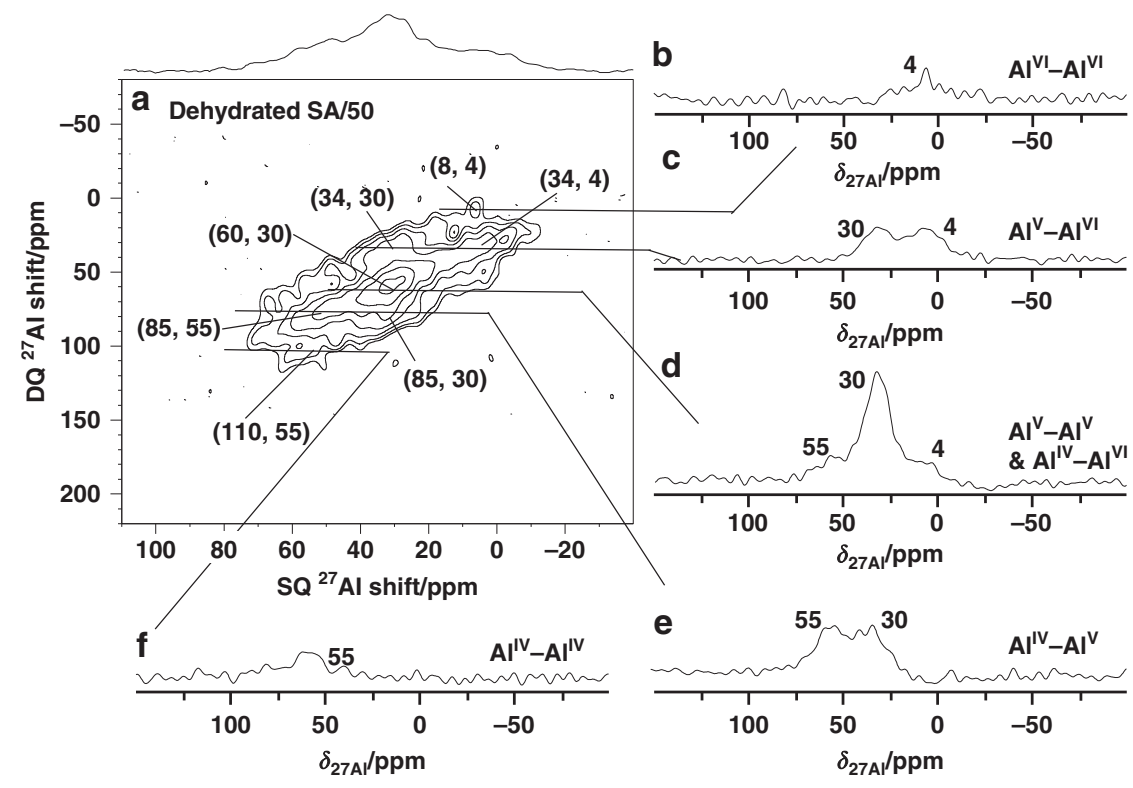

Fig. $3{ }^{27}$ AI DQ-SQ 2D NMR spectrum. a ${ }^{27} \mathrm{Al} 2 \mathrm{D}$ NMR spectrum recorded at $18.8 \mathrm{~T}$ with $\nu_{\mathrm{R}}=20 \mathrm{kHz}$ of SA/50 dehydrated at $723 \mathrm{~K}$ for $12 \mathrm{~h}$ under vacuum. b-f Rows extracted from the $2 \mathrm{D}$ spectrum corresponding to the various auto-correlations and cross peaks. All rows are plotted with the same intensity scale. 
a
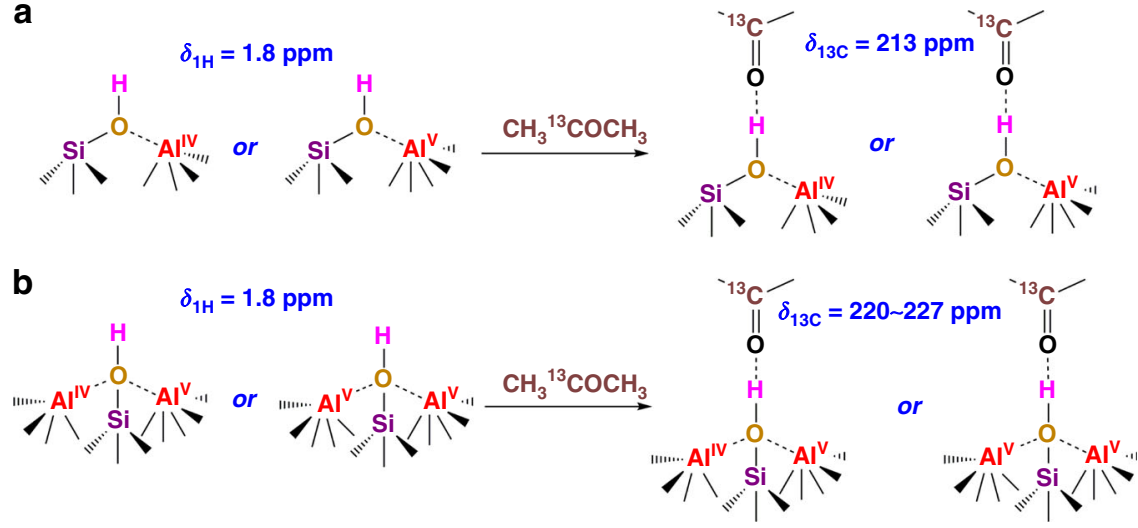

Fig. 4 Proposed models for BAS on ASA generated by. a one Al center per SiOH for moderate BAS, and $\mathbf{b}$ two $\mathrm{Al}$ centers per SiOH group, leading to moderate or zeolitic acidity strengths. The acid strength is estimated by measuring the ${ }^{13} \mathrm{C}$ isotropic chemical shift of $\mathrm{CH}_{3}{ }^{13} \mathrm{COCH}_{3}$, which is loaded on dehydrated samples on a vacuum line, followed by evacuation at room temperature for $1 \mathrm{~h}$ to remove weakly adsorbed molecules.

is mainly correlated with $\mathrm{Al}^{\mathrm{V}}$ sites, acting as LAS. After ammonia adsorption, the ${ }^{27} \mathrm{Al}$ DQ-SQ $2 \mathrm{D}$ spectrum is broadened (Supplementary Fig. 5). However, the majority of the $\mathrm{Al}^{\mathrm{IV}}-\mathrm{Al}^{\mathrm{V}}$ and $\mathrm{Al}^{\mathrm{V}}-\mathrm{Al}^{\mathrm{V}}$ correlations are still observed. In the ${ }^{1} \mathrm{H}$ DQ-SQ spectrum of dehydrated SA50 (Supplementary Note 2) no signal of $\mathrm{Al}(\mathrm{OH}) \mathrm{Al}$ groups at ca. 1.7-2.7 ppm could be detected ${ }^{6}$, indicating a low probability of $\mathrm{Al}-\mathrm{Al}$ correlations originating from $\mathrm{Al}^{\mathrm{IV}}-\mathrm{OH}-\mathrm{Al}^{\mathrm{V}}$ and $\mathrm{Al}^{\mathrm{V}}-\mathrm{OH}-\mathrm{Al}^{\mathrm{V}}$ groups in alumina domains. Furthermore, these sites do not protonate ammonia and hence, the corresponding ${ }^{27} \mathrm{Al}$ correlation will not be significantly broadened in the presence of ammonia. Conversely ammonia can be protonated by surface BAS ( $\mathrm{SiOH}$ with nearby $\mathrm{Al}$ ) on ASAs, which explains the peak broadening observed in the ${ }^{27} \mathrm{Al} \mathrm{DQ}-\mathrm{SQ}$ 2D spectrum after ammonia adsorption (Supplementary Fig. 5). This broadening has been proposed by the synergy of $\mathrm{Al}^{\mathrm{IV}}-\mathrm{Al}^{\mathrm{V}}$ and $\mathrm{Al}^{\mathrm{V}}-\mathrm{Al}^{\mathrm{V}}$ spin pairs in the local structure of the same $\mathrm{SiOH}$ group (Al-SiOH-Al) with enhanced acid strength.

Acidity enhancement by the synergy of nearby Al species. In $\mathrm{SA} / 10$, as in most ASAs, only a moderate acidity strength $\left(\delta_{13 \mathrm{C}}=\right.$ 213 ppm probed with $\mathrm{CH}_{3}{ }^{13} \mathrm{COCH}_{3}$ ) was detected ${ }^{5}$. Figure 1 and Supplementary Fig. 1 show that the $\mathrm{Al}^{\mathrm{IV}}$ and $\mathrm{Al}^{\mathrm{V}}$ species are welldistributed on ASA without obvious correlations, e.g. SA/10. Moreover, bridging $\mathrm{OH}$ groups $\left(\delta_{1 \mathrm{H}}=3.6-5.2 \mathrm{ppm}\right)$ were not detected in ${ }^{1} \mathrm{H}$ NMR $1 \mathrm{D}$ experiments (Supplementary Fig. 2b). Therefore, the moderate BAS strength in SA/10 is proposed to be generated by one $\mathrm{Al}$ center interacting with the neighboring silanol group and in that way decreasing the electron density of the $\mathrm{O}$ atom, leading to the formation of one acid $\mathrm{SiOH}$ site (BAS), as shown in Fig. 4a. This arrangement is similar to the PBS model proposed in previous theoretical calculation studies, where a $\mathrm{SiOH}$ group electrostatically interacts with an acceptor $\mathrm{Al}$ center $\left(\mathrm{Al}^{\mathrm{IV}}\right.$ or $\left.\mathrm{Al}^{\mathrm{V}}\right)$, but is not covalently bonded as bridging $\mathrm{OH}$ groups in zeolites 24,31 .

In $\mathrm{SA} / 50$, two $\mathrm{Al}$ centers (two $\mathrm{Al}^{\mathrm{V}}$ or one $\mathrm{Al}^{\mathrm{V}}$ and one $\mathrm{Al}^{\mathrm{IV}}$ ) can be in the proximity of the same $\mathrm{SiOH}$ group. In a previous study, based on DNP (dynamic nuclear polarization) and firstprinciple calculations, several possible models for two or more $\mathrm{Al}$ centers in the vicinity of a $\mathrm{SiOH}$ group on ASA, prepared by chemical liquid deposition of $\mathrm{SiO}_{2}$ on $\mathrm{Al}_{2} \mathrm{O}_{3}$, have been proposed by Valla and coworkers ${ }^{21}$. In ASAs, BAS are formed at the surface consisting of mixed alumina and silica and thus a wide distribution of Al species in the local structure of Si species can be expected, particularly in the Al-rich phase, as exemplified for ASAs prepared by chemical liquid deposition of $\mathrm{SiO}_{2}$ on $\mathrm{Al}_{2} \mathrm{O}_{3}{ }^{21}$. However, these models do not account for the enhanced
Brønsted acidity of flame-made ASAs with high Al content, such as SA/50. Therefore, here we propose a structural model of $\mathrm{BAS}$, in which $\mathrm{Al}^{\mathrm{IV}}$ and $\mathrm{Al}^{\mathrm{V}}$ sites or two $\mathrm{Al}^{\mathrm{V}}$ sites interact with the same $\mathrm{SiOH}$ group (see Fig. 4b), most likely via pseudobridging $\mathrm{OH}$ groups as often proposed ${ }^{24,32}$, and withdraw electrons from the oxygen of the near $\mathrm{SiOH}$ group, thus enhancing its Brønsted acidity. The structural models shown in Fig. 4 bear similarities with oxygen tri- and tetra-coordinated clusters, which have been proposed earlier in ASA prepared by chemical liquid deposition of $\mathrm{SiO}_{2}$ on $\mathrm{Al}_{2} \mathrm{O}_{3}$ and aluminosilicates glasses $^{21,58}$. The formation of oxygen tri- or tetra- coordinated clusters is driven by the increased ionicity of these materials at higher $\mathrm{Al}$ content due to the difference in electronegativity between $\mathrm{Si}$ and $\mathrm{Al}$ atoms ${ }^{31,59}$.

However, one or more $\mathrm{Al}$ centers solely covalently bound to the $\mathrm{Si}$ atoms of the silanols are unable to protonate adsorbed ammonia, since the silanolate cannot be efficiently stabilized after deprotonation 31,60 . Proton transfer from silanol to the guest molecule can be promoted by the stabilization of the conjugated base (silanolate). The silanolate can be stabilized by a neighboring unsaturated $\mathrm{Al}$ center via PBS model ${ }^{31,60-62}$, such as proposed in Fig. $4 \mathrm{a}$, which is often characterized by moderate acidity.

Here, we propose a model as shown in Fig. 4b, for the formation of BAS on SA/50 with an acidity comparable to zeolites. Compared to Fig. 4a for SA/10, the second neighboring unsaturated $\mathrm{Al}$ center involved as an acceptor is able to further stabilize the formed silanolate, and thus to promote the proton transfer. Besides, the extra $\mathrm{Al}$ center(s) may further withdraw electrons from the $\mathrm{O}$ atom from neighboring $\mathrm{SiOH}$ that significantly enhances the BAS strength (up to $\left.\delta_{13 \mathrm{C}}=227 \mathrm{ppm}\right)^{5}$, to a higher extent than that of zeolite H-ZSM-5 $\left(\delta_{13 \mathrm{C}}=223 \mathrm{ppm}\right)^{55}$, similar to that of dealuminated zeolite $\mathrm{H}-\mathrm{Y}\left(\delta_{13 \mathrm{C}}=228 \mathrm{ppm}\right)^{17}$. The proposed model is similar to those reported for zeolites where an ionic effect induced by extra-framework $\mathrm{Al}$ species can enhance the Brønsted acid strength of bridging $\mathrm{OH}$ groups ${ }^{17}$. Therefore, the synergy of two $\mathrm{Al}^{\mathrm{V}}$ or one $\mathrm{Al}^{\mathrm{IV}}$ and one $\mathrm{Al}$ centers with nearby $\mathrm{SiOH}$ groups is expected to significantly enhance the acid strength of BAS in the ASA.

In situ ${ }^{1}$ H MAS NMR study on acidity enhancement of BAS. In this work, we show that the proximity between one $\mathrm{SiOH}$ group and two $\mathrm{Al}$ sites can remarkably enhance the Brønsted acidity in $\mathrm{ASAs}^{5,16}$. The activation of the $\mathrm{C}-\mathrm{H}$ bond in hydrocarbon conversion often requires solid acids containing strong BAS. The activation of the $\mathrm{C}-\mathrm{H}$ bond in benzene, the simplest aromatic compound, has been extensively studied using H/D exchange 

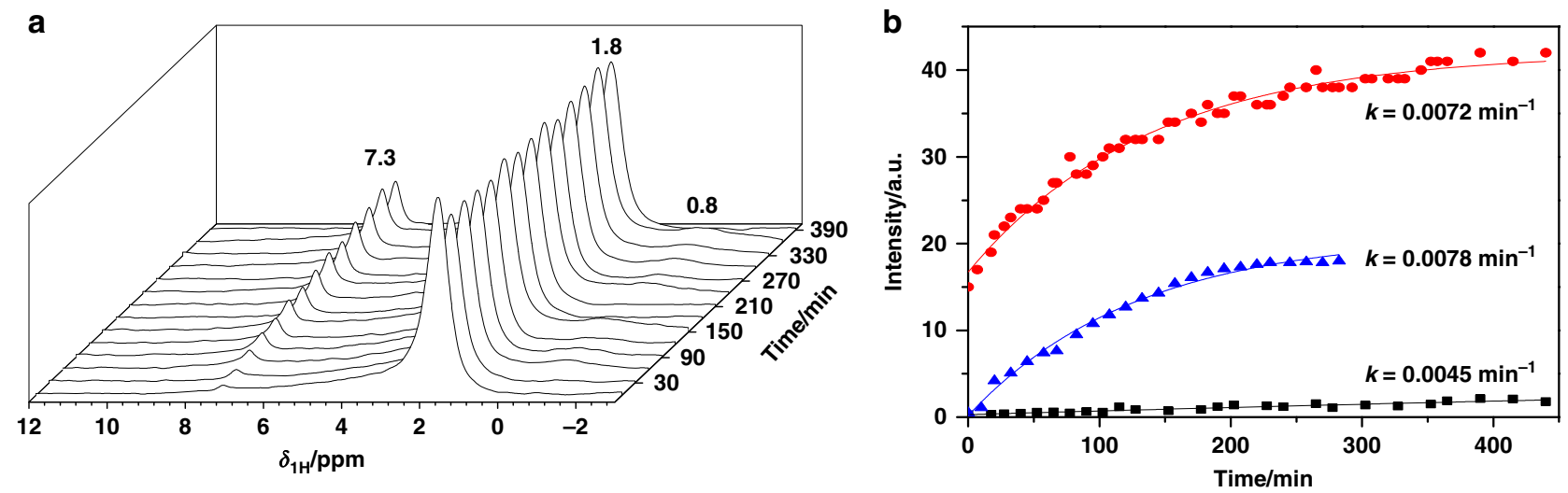

Fig. 5 Catalytic performance of ASA in $\mathbf{H} / \mathbf{D}$ exchange with $\mathbf{C}_{\mathbf{6}} \mathbf{D}_{6} .{ }^{1} \mathrm{H}$ MAS spectra recorded at $9.4 \mathrm{~T}$ of dehydrated catalysts, a stack plot spectra recorded during $H / D$ exchange of $C_{6} D_{6}$ loaded over dehydrated $S A / 50$ at $313 \mathrm{~K}$, with a loading of one benzene molecule per BAS; $\boldsymbol{b}$ Kinetics and $H / D$ exchange rates $k$ between deuterons bound to the aromatic rings of $\mathrm{C}_{6} \mathrm{D}_{6}(99.6 \%$ ) and $\mathrm{BAS}$ at $313 \mathrm{~K}$ in $\mathrm{H}-\mathrm{ZSM}-5$ (top), SA/50 (middle) and SA/10 (bottom).

experiments, which is of great importance to understand the alkylation processes of aromatic compounds ${ }^{8-12}$. The $\mathrm{H} / \mathrm{D}$ exchange carried out between $\mathrm{C}_{6} \mathrm{D}_{6}$ and surface BAS (bridging $\mathrm{OH}$ on zeolite H-ZSM-5 and acidic $\mathrm{SiOH}$ groups on ASA) was confirmed by ${ }^{1} \mathrm{H}$ solid-state NMR (Supplementary Fig. 6).

On H-ZSM-5 zeolite, the three ${ }^{1} \mathrm{H}$ signals of $\mathrm{H}-\mathrm{ZSM}-5$ zeolite at 7.5, 4.0 and $1.8 \mathrm{ppm}$ (see Supplementary Fig. 6a) are assigned to hydrogen atoms bound to aromatic rings, bridging $\mathrm{OH}$ (SiOHAl) groups and terminal $\mathrm{SiOH}$ groups, respectively. After $\mathrm{H} / \mathrm{D}$ exchange reaction, the intensity of $\mathrm{SiOH}$ groups remained unchanged while that of bridging $\mathrm{OH}$ groups decreased with increasing intensity of the aromatic hydrogens. This indicates that the H/D exchange occurred between the benzene- $d_{6}$ and the bridging $\mathrm{OH}$ groups (e.g. $\mathrm{SiOHAl}$ ), rather than with the terminal $\mathrm{SiOH}$ groups $\left(\delta_{1 \mathrm{H}}=1.8 \mathrm{ppm}\right)$.

Conversely, no bridging $\mathrm{OH}$ groups could be observed at 3.5-5.2 ppm on SA/50 (see Supplementary Fig. $6 \mathrm{~b})^{6}$, while the signal of protons bound to the aromatic rings was observed at $7.3 \mathrm{ppm}$. As shown in the stack plot of the ${ }^{1} \mathrm{H}$ MAS spectra recorded during $H / D$ exchange of benzene- $d_{6}$ loaded over dehydrated SA/50 (Fig. 5a), the intensity of the terminal $\mathrm{SiOH}$ groups $\left(\delta_{1 \mathrm{H}}=1.8 \mathrm{ppm}\right)$ decreased as a function of time, while that of protons bound to aromatic rings $\left(\delta_{1 \mathrm{H}}=7.3 \mathrm{ppm}\right)$ increased. This demonstrates that the H/D exchange occurred between $\mathrm{C}_{6} \mathrm{D}_{6}$ and the acidic $\mathrm{SiOH}$ groups of ASA. It must be reminded that Lewis acid aluminum sites cannot exchange $\mathrm{H}$ with $\mathrm{C}_{6} \mathrm{D}_{6}$ (see Supplementary Note 3 ).

The reaction rate, $k$, for the $\mathrm{C}_{6} \mathrm{D}_{6}-\mathrm{SiOH}$ exchange can be utilized to evaluate the relative strength of BAS in silica-alumina catalysts under the same conditions. As described in the Methods section, one molecule of $\mathrm{C}_{6} \mathrm{D}_{6}$ per Brønsted acid site was quantitatively loaded, and thus, a higher $k$ value indicates a higher acid strength ${ }^{63-65}$. The rate of the H/D exchange reaction over different catalysts upon loading one $\mathrm{C}_{6} \mathrm{D}_{6}$ per BAS at $313 \mathrm{~K}$ was determined by fitting the evolution of the signal intensity of aromatic protons as a function of reaction time $\mathrm{e}^{9,12}$. The obtained $k$ values are shown in Fig. 5b. Evidently, SA/10 with mainly moderate BAS was virtually inactive in the reaction, resulting in a small $k$ value, while zeolite H-ZSM- 5 with strong BAS provided a much higher reaction rate $\left(k=0.0072 \mathrm{~min}^{-1}\right)$. A similar value, $k$ of $0.0078 \mathrm{~min}^{-1}$, was obtained with SA/50 under the same conditions, hinting to the existence of strong BAS in SA/50 with a strength comparable to that of zeolite H-ZSM-5. Considering the structural difference between $\mathrm{SA} / 10$ and SA/50, it shows that the proximity between more than one $\mathrm{Al}$ center and $\mathrm{SiOH}$ group in ASA with high Al content, such as SA/50, gives rise to BAS with zeolitic strength.
Stability test of ASA catalysts. Besides their enhanced surface Brønsted acidity, the high stability of ASAs under various conditions is crucial for efficient catalysis. Current ASAs were thus firstly tested in liquid-phase glucose dehydration to 5hydroxymethylfurfural (HMF), requiring LAS for glucose isomerization to fructose and BAS for fructose dehydration ${ }^{48}$. The catalytic reaction results are summarized in Supplementary Note 4, 5, and Supplementary Fig. 7. The reusability of ASA was tested with $\mathrm{SA} / 50$, which exhibited the best performance under the same conditions. After five recycle runs, no significant loss of catalytic activity could be observed (Supplementary Note 5). This is attributed to the high stability of SA/50 in the liquid phase glucose dehydration. In liquid phase reactions under heating, dealumination could cause the modification of surface acid sites. The comparison of Supplementary Fig. 12a, b demonstrates that aluminum species in SA/50 are stable without dealumination upon water treatment at $433 \mathrm{~K}$ for $2 \mathrm{~h}$ (Supplementary Note 6). Therefore, the synergy of Lewis acidic $\mathrm{Al}^{\mathrm{V}}$ and enhanced Brønsted acidity renders these ASAs promising bifunctional catalysts for Brønsted-Lewis acid-catalyzed reaction, such as the glucose dehydration to HMF.

It is noteworthy to point out the high stability of the BAS with enhanced strength when they are exposed to high temperature $(1073 \mathrm{~K})$ calcination (regeneration temperature in fluid catalytic cracking, Supplementary Fig. 12c) or to a liquid-phase conversion of glyceraldehyde in ethanol (Supplementary Fig. 12d). Two or more $\mathrm{Al}$ centers nearby $\mathrm{SiOH}$ groups in the amorphous silica network did not leach out from the catalysts after five recycle uses in a batch reaction with ultrasonic washing (Supplementary Fig. 12d), as confirmed by the lack of detectable $\mathrm{Al}$ species in the reaction mixture. Conversely, a similar treatment caused strong leaching of extra-framework aluminum species in zeolites, which exhibited enhanced acidity of BAS via the synergy of extraframework aluminum and BAS. This leaching led to a significant activity loss of these zeolites (Supplementary Note 7) as confirmed by $1 \mathrm{D}^{27} \mathrm{Al}$ NMR experiments (Supplementary Note 8 ).

\section{Discussion}

In conclusion, a remarkable synergy between two $\mathrm{Al}$ centers $\left(\mathrm{Al}^{\mathrm{V}}\right.$ $\mathrm{Al}^{\mathrm{IV}}$ or $\mathrm{Al}^{\mathrm{V}}-\mathrm{Al}^{\mathrm{V}}$ ) close to the same $\mathrm{SiOH}$ group has been evidenced in flame-made amorphous silica-alumina (ASA) by $2 \mathrm{D}$ ${ }^{27} \mathrm{Al}$ and ${ }^{1} \mathrm{H}$ DQ-SQ NMR experiments, and analysis of the 3D spatial elemental distribution of $\mathrm{Al}$ and $\mathrm{Si}$ by APT. The study revealed that compared to the widely accepted model of one $\mathrm{Al}$ center per $\mathrm{SiOH}$ group with moderate strength $\left(\delta_{13 \mathrm{C}}=213 \mathrm{ppm}\right)^{5}$, two proximate Al centers can strongly decrease the electron density from a neighboring silanol oxygen and thereby can 
significantly boost its acid strength (with $\delta_{13 \mathrm{C}}=227 \mathrm{ppm}$ for $\left.\mathrm{CH}_{3}{ }^{13} \mathrm{COCH}_{3}\right)$ to a value higher than that of H-ZSM-5 $\left(\delta_{13 \mathrm{C}}=\right.$ $223 \mathrm{ppm})^{55}$, or even reaching that of dealuminated zeolite $\mathrm{HY}$ $\left(\delta_{13 \mathrm{C}}=228 \mathrm{ppm}\right)^{17}$. These BAS with zeolitic strength have been evidenced by comparative $H / D$ exchange experiments with $C_{6} D_{6}$. Furthermore, the synergy between BAS with zeolitic strength and LAS afforded a much higher HMF yield (38\%) than catalysts with moderate BAS strength (e.g. SA/10 and [Al]MCM-41). The achieved yield was comparable to that realized with metal-doped zeolites (33\%) at a higher temperature. The present study highlights a promising route for generating BAS with zeolitic strength and high stability on ASAs, which could facilitate improved catalytic performances in a wide range of applications, including acid and multifunctional catalysis.

\section{Methods}

APT sample preparation and measurement method. A drop of the diluted dispersed ASA nanoparticles in methanol $(\approx 0.01 \mathrm{~mol} / \mathrm{L})$ was placed onto a Si flat wafer, which was covered by a $150-\mathrm{nm}$ thick protective $\mathrm{Cr}$ layer in Leica EM ACE600. Needle-shaped APT specimens were prepared from the Si flat sample by a site-specific lift-out procedure using a FEI G4 CX focused ion beam (FIB)/scanning electron microscope ${ }^{66}$. The APT experiments were conducted on a CAMECA LEAP $5000 \mathrm{XR}$ instrument equipped with an ultraviolet laser with a spot size of $2 \mu \mathrm{m}$ and a wavelength of $355 \mathrm{~nm}$. The detection efficiency of this state-of-the-art microscope is ca. $54 \%$. Data were acquired in laser pulsing mode at a specimen temperature of $50 \mathrm{~K}$, with a target evaporation rate of 3 ions per 1000 pulses, a pulsing rate of $200 \mathrm{kHz}$, and a laser pulse energy of $50 \mathrm{pJ}$. The APT data were reconstructed and analyzed using the commercial IVAS $3.6 .14^{\mathrm{m}}$ software.

NMR experimental details. Before each experiment, the samples in glass tubes were dehydrated at $723 \mathrm{~K}$ for $12 \mathrm{~h}$ at a pressure lower than $10^{-2}$ bar. Subsequently, the samples were transferred into the MAS NMR rotors under dry $\mathrm{N}_{2}$ inside a glove box. These ammonia-loaded samples were prepared by dehydrated samples loaded with ammonia on a vacuum line, followed by evacuation at $393 \mathrm{~K}$ for $1 \mathrm{~h}$ to remove weakly physisorbed molecules.

All ${ }^{1} \mathrm{H}$ and ${ }^{27} \mathrm{Al}$ NMR spectra were recorded on a Bruker Avance III $800 \mathrm{MHz}$ spectrometer equipped with $3.2 \mathrm{~mm}$ MAS rotors spinning at $20 \mathrm{kHz}$. For ${ }^{1} \mathrm{H}$ DQSQ 2D experiments, the ${ }^{1} \mathrm{H}$ DQ coherences were excited and reconverted by applying the symmetry-based $\mathrm{R} 12_{2}^{5}$ scheme $e^{67}$, which reintroduces the ${ }^{1} \mathrm{H}-{ }^{1} \mathrm{H}$ dipolar interactions under MAS. The ${ }^{1} \mathrm{H}$ radio frequency $(\mathrm{rf})$ amplitudes for the $\pi /$ 2 pulse and R $12_{2}^{5}$ scheme were equal to $v_{1}=75$ and $60 \mathrm{kHz}$, respectively. The length of the excitation recoupling scheme was equal to that of the reconversion and ranged from 250 to $300 \mu$ s, depending on the experiment. ${ }^{1} \mathrm{H}$ DQ-SQ $2 \mathrm{D}$ spectra resulted from averaging 32 to 128 transients with recycle delay of 1 to $5 \mathrm{~s}$, resulting in a total experimental time of 2 to $4 \mathrm{~h}$. During ${ }^{27} \mathrm{Al}$ DQ-SQ 2D experiments, selective central transition (CT) $\pi / 2$ and $\pi$-pulses of 8 and $16 \mu$ s, that is, an rf amplitude of about $10 \mathrm{kHz}$, were applied. The ${ }^{27} \mathrm{Al}$ two-spin DQ coherences were excited and reconverted by applying the $\mathrm{BR} 2{ }_{2}^{1}$ pulse sequence ${ }^{36}$, which reintroduces the ${ }^{27} \mathrm{Al}-{ }^{27} \mathrm{Al}$ dipolar interactions under MAS. The lengths of the excitation and reconversion periods were equal and ranged from 800 to $1200 \mu \mathrm{s}$, depending on the experiment. The rf amplitude applied during the $\mathrm{BR} 2 \frac{1}{2}$ pulse sequence was $6.6 \mathrm{kHz}$, which corresponds to a nutation frequency of $20 \mathrm{kHz}$ for the ${ }^{27} \mathrm{Al} \mathrm{CT}$. Furthermore, the Hyper-Secant (HS) scheme was applied before the $\mathrm{BR} 2{ }_{2}^{1}$ excitation ${ }^{68}$, in order to enhance the ${ }^{27} \mathrm{Al} \mathrm{CT}$ polarization by saturating the satellite transitions $\mathrm{s}^{69,70}$. HS employed a shaped pulse lasting $4 \mathrm{~ms}$ with an $\mathrm{rf}$ field amplitude of $16 \mathrm{kHz}$ and a frequency sweep of $20 \mathrm{kHz}$ around an offset of $200 \mathrm{kHz}$ with respect to the CT. ${ }^{27} \mathrm{Al}$ DQ-SQ 2D spectra resulted from averaging 14,400 and 3200 transients for SA/10 (Fig. 1) and SA/50 (Fig. 3) with recycle delay of $0.2 \mathrm{~s}$, resulting in a total experimental time of 25.3 and $5.7 \mathrm{~h}$, respectively. The ${ }^{1} \mathrm{H}$ isotropic chemical shifts were referenced to tetramethylsilane using the resonance of adamantane $(1.83 \mathrm{ppm})$ as a secondary reference, whereas the ${ }^{27} \mathrm{Al}$ ones were referenced to $1 \mathrm{M}$ solution $\mathrm{Al}\left(\mathrm{NO}_{3}\right)_{3}$.

In situ ${ }^{1} \mathbf{H}$ MAS NMR Spectroscopy of $\mathbf{H} / \mathbf{D}$ exchange with $\mathbf{C}_{\mathbf{6}} \mathbf{D}_{\mathbf{6}} \cdot{ }^{1} \mathrm{H}$ MAS NMR spectra of $\mathrm{H} / \mathrm{D}$ exchange with $\mathrm{C}_{6} \mathrm{D}_{6}$ was carried out on a Bruker Avance III 400 WB spectrometer at the Larmor frequency of $400.1 \mathrm{MHz}$ with $4 \mathrm{~mm}$ MAS rotors spinning at $8 \mathrm{kHz}$. Spectra were recorded after single-pulse $\pi / 2$ excitation with repetition times of $20 \mathrm{~s}$ and 8 scans. Prior to measurements, all samples were dehydrated at $723 \mathrm{~K}$ in vacuum (pressure $<10^{-2}$ bar) for $12 \mathrm{~h}$ in glass tubes. The density of BAS on all dehydrated samples was determined by quantitative ${ }^{1} \mathrm{H}$ MAS NMR experiments using $\mathrm{NH}_{3}$ as probe molecules. The total number of BAS was calculated based on the BAS density and weight of the sample. A known amount of dehydrated samples was transferred into the MAS rotors under dry nitrogen gas inside a glove box, sealed and utilized for in-situ loading on a vacuum line. The loading pressure of benzene- $d_{6}(99.6 \%$, Cambridge Isotope Laboratories, Inc.) was calculated and controlled according to the total number of BAS and known volume of the vacuum line to ensure one molecule of benzene- $d_{6}$ per BAS. Then the sample was cooled down by liquid nitrogen till nearly no pressure could be detected. Subsequently, the loaded samples in the MAS rotors were kept $10 \mathrm{~min}$ at room temperature under dry nitrogen gas inside a glove box for better diffusion. The $\mathrm{H} / \mathrm{D}$ experiments were performed by heating the MAS rotor at $313 \mathrm{~K}$ in a variabletemperature probe for ${ }^{1} \mathrm{H}$ MAS NMR investigations. The concentration of protons bound to the aromatic rings was calculated as the ratio between the integrated intensity of the aromatic ${ }^{1} \mathrm{H}$ signal and the number of Brønsted acid sites. The rate $k$ of the H/D exchange between the deuterated molecules and the acidic $\mathrm{OH}$ groups (BAS) is described by an exponential relationship ${ }^{9}$

$$
I(t)=I(\infty)[1-b \exp \{-k t\}]
$$

where $I(t)$ and $I(\infty)$ denote the intensities of the ${ }^{1} \mathrm{H}$ MAS NMR signal of the aromatic rings at the observation time $t$ and $t \rightarrow+\infty$ in the equilibrium state, respectively. The $b$ parameter describes the exchange at $t=0$, which corresponds to the start of the H/D exchange experiment, i.e. when the temperature was increased from ca. $293 \mathrm{~K}$ to that of the reaction.

\section{Data availability}

Raw data are available from the authors upon reasonable request.

Received: 1 September 2018; Accepted: 25 November 2019; Published online: 13 January 2020

\section{References}

1. Corma, A. Inorganic solid acids and their use in acid-catalyzed hydrocarbon reactions. Chem. Rev. 95, 559-614 (1995).

2. Huber, G. W., Iborra, S. \& Corma, A. Synthesis of transportation fuels from biomass: chemistry, catalysts, and engineering. Chem. Rev. 106, 4044-4098 (2006).

3. Wang, Z. et al. Acidity enhanced [Al]MCM-41 via ultrasonic irradiation for the Beckmann rearrangement of cyclohexanone oxime to $\varepsilon$-caprolactam. J. Catal. 358, 71-79 (2018).

4. Wang, Z., Wang, L., Jiang, Y., Hunger, M. \& Huang, J. Cooperativity of Brønsted and Lewis acid sites on zeolite for glycerol dehydration. ACS Catal. 4, 1144-1147 (2014).

5. Huang, J., van Vegten, N., Jiang, Y., Hunger, M. \& Baiker, A. Increasing the Brønsted acidity of flame-derived silica/alumina up to zeolitic strength. Angew. Chem. Int. Ed. 49, 7776-7781 (2010).

6. Jiang, Y., Huang, J., Dai, W. \& Hunger, M. Solid-state nuclear magnetic resonance investigations of the nature, property, and activity of acid sites on solid catalysts. Solid State Nucl. Magn. Reson. 39, 116-141 (2011).

7. Fang, H. et al. New insights into the effects of acid strength on the solid acidcatalyzed reaction: theoretical calculation study of olefinic hydrocarbon protonation reaction. J. Phys. Chem. C. 114, 10254-10264 (2010).

8. Huang, J., Jiang, Y., Marthala, V. R. R., Ooi, Y. S. \& Hunger, M. Regioselective $\mathrm{H} / \mathrm{D}$ exchange at the side-chain of ethylbenzene on dealuminated zeolite $\mathrm{H}-\mathrm{Y}$ studied by in situ MAS NMR-UV/Vis spectroscopy. ChemPhysChem $\mathbf{9}$, 1107-1109 (2008)

9. Huang, J. et al. In situ H-1 MAS NMR investigations of the H/D exchange of alkylaromatic hydrocarbons on zeolites H-Y, La,Na-Y, and H-ZSM-5. Microporous Mesoporous Mater. 99, 86-90 (2007).

10. Huang, J., Jiang, Y., Marthala, V. R. R. \& Hunger, M. Insight into the mechanisms of the ethylbenzene disproportionation: Transition state shape selectivity on zeolites. J. Am. Chem. Soc. 130, 12642-12644 (2008).

11. Beck, L. W., Xu, T., Nicholas, J. B. \& Haw, J. F. Kinetic NMR and densityfunctional study of benzene H/D exchange in zeolites, the simplest aromaticsubstitution. J. Am. Chem. Soc. 117, 11594-11595 (1995).

12. Mildner, T. \& Freude, D. Proton transfer between Brønsted sites and benzene molecules in zeolites H-Y studies by in situ MAS NMR. J. Catal. 178, 309-314 (1998).

13. Li, Y., Li, L. \& Yu, J. H. Applications of Zeolites in Sustainable Chemistry. Chem 3, 928-949 (2017).

14. Coppola, G. M., Schuster, H. F. $\alpha$-Hydroxy acids in enantioselective synthesis (WileyVCH Verteg GmbH, 1997).

15. Wang, Z., Jiang, Y., Baiker, A. \& Huang, J. Efficient acid-catalyzed conversion of phenylglyoxal to mandelates on flame-derived silica/alumina. ACS Catal. $\mathbf{3}$, 1573-1577 (2013).

16. Wang, Z. C. et al. Brønsted acid sites based on penta-coordinated aluminum species. Nat. Commun. 7, 13820 (2016).

17. Li, S. et al. Brønsted/Lewis acid synergy in dealuminated HY zeolite: A combined solid-state NMR and theoretical calculation study. J. Am. Chem. Soc. 129, 11161-11171 (2007). 
18. Weitkamp, J., and Hunger M. Acid and base catalysis on zeolites. In Studies in Surface Science and Catalysis, Ejka, J., van Bekkum, H., Corma, A., Schüth, F., ed. (Elsevier: Amsterdam, 2007), pp. 787-835.

19. Mouat, A. R. et al. Highly dispersed $\mathrm{SiOx} / \mathrm{Al} 2 \mathrm{O} 3$ catalysts illuminate the reactivity of isolated silanol sites. Angew. Chem. Int. Ed. 54, 13346-13351 (2015).

20. Mouat, A. R., Kobayashi, T., Pruski, M., Marks, T. J. \& Stair, P. C. Direct spectroscopic evidence for isolated silanols in $\mathrm{SiOx} / \mathrm{Al} 2 \mathrm{O} 3$ and their formation mechanism. J. Phys. Chem. C. 121, 6060-6064 (2017).

21. Valla, M. et al. Atomic description of the interface between silica and alumina in aluminosilicates through dynamic nuclear polarization surface-enhanced NMR spectroscopy and first-principles calculations. J. Am. Chem. Soc. 137, 10710-10719 (2015).

22. Wang, Z. et al. One-step room-temperature synthesis of [Al]MCM-41 materials for the catalytic conversion of phenylglyoxal to ethylmandelate. ChemCatChem 5, 3889-3896 (2013).

23. Luo, Q. et al. Using trimethylphosphine as a probe molecule to study the acid states in Al-MCM-41 materials by solid-state NMR spectroscopy. J. Phys. Chem. B 107, 2435-2442 (2003).

24. Chizallet, C. \& Raybaud, P. Pseudo-bridging silanols as versatile Brønsted acid sites of amorphous aluminosilicate surfaces. Angew. Chem. Int. Ed. 48, 2891-2893 (2009).

25. Mortier, W. J. Zeolite electronegativity related to physicochemical properties. J. Catal. 55, 138-145 (1978).

26. Kalirai, S., Paalanen, P. P., Wang, J., Meirer, F. \& Weckhuysen, B. M. Visualizing dealumination of a single zeolite domain in a real-life catalytic cracking particle. Angew. Chem. Int. Ed. 55, 11134-11138 (2016).

27. Dapsens, P. Y., Mondelli, C. \& Perez-Ramirez, J. Highly selective Lewis acid sites in desilicated MFI zeolites for dihydroxyacetone isomerization to lactic acid. ChemSusChem 6, 831-839 (2013).

28. Loewenstein, W. The distribution of aluminum in the tetrahedra of silicates and aluminates. Am. Min. 39, 92-96 (1954).

29. Hensen, E. J. M. et al. Acidity characterization of amorphous silica-alumina. J. Phys. Chem. C. 116, 21416-21429 (2012).

30. Eichler, U., Brandle, M. \& Sauer, J. Predicting absolute and site specific acidities for zeolite catalysts by a combined quantum mechanics interatomic potential function approach. J. Phys. Chem. B 101, 10035-10050 (1997).

31. Chizallet, C. \& Raybaud, P. Acidity of amorphous silica-alumina: from coordination promotion of Lewis sites to proton transfer. ChemPhysChem $\mathbf{1 1}$, 105-108 (2010).

32. Perras, F. A. et al. Shedding light on the atomic-scale structure of amorphous silica-alumina and its Brønsted acid sites. Phys. Chem. Chem. Phys. 21, 19529-19537 (2019).

33. $\mathrm{Yu}, \mathrm{Z}$. et al. Insights into the dealumination of zeolite $\mathrm{HY}$ revealed by sensitivity-enhanced Al-27 DQ-MAS NMR spectroscopy at high field. Angew. Chem. Int. Ed. 49, 8657-8661 (2010).

34. Lee, D. et al. Enhanced solid-state NMR correlation spectroscopy of quadrupolar nuclei using dynamic nuclear polarization. J. Am. Chem. Soc. 134, 18491-18494 (2012).

35. Li, S. H. et al. Extra-framework aluminium species in hydrated faujasite zeolite as investigated by two-dimensional solid-state NMR spectroscopy and theoretical calculations. Phys. Chem. Chem. Phys. 12, 3895-3903 (2010).

36. Wang, Q. et al. Double-quantum homonuclear NMR correlation spectroscopy of quadrupolar nuclei subjected to magic-angle spinning and high magnetic field. J. Magn. Reson. 200, 251-260 (2009).

37. Li, T. et al. Atomic imaging of carbon-supported Pt, Pt/Co, and Ir@Pt nanocatalysts by atom-probe tomography. ACS Catal. 4, 695-702 (2014).

38. Eley, C. et al. Nanojunction-mediated photocatalytic enhancement in heterostructured $\mathrm{CdS} / \mathrm{ZnO}, \mathrm{CdSe} / \mathrm{ZnO}$, and $\mathrm{CdTe} / \mathrm{ZnO}$ nanocrystals. Angew. Chem. Int. Ed. 53, 7838-7842 (2014).

39. Schmidt, J. E., Peng, L. Q., Poplawsky, J. D. \& Weckhuysen, B. M. Nanoscale chemical imaging of zeolites using atom probe tomography. Angew. Chem. Int. Ed. 57, 10422-10435 (2018).

40. Schmidt, J. E. et al. Isolating clusters of light elements in molecular sieves with atom probe tomography. J. Am. Chem. Soc. 140, 9154-9158 (2018).

41. Schmidt, J. E. et al. Coke formation in a zeolite crystal during the methanol-tohydrocarbons reaction as studied with atom probe tomography. Angew. Chem. Int. Ed. 55, 11173-11177 (2016).

42. Schmidt, J. E., Oord, R., Guo, W., Poplawsky, J. D. \& Weckhuysen, B. M. Nanoscale tomography reveals the deactivation of automotive copperexchanged zeolite catalysts. Nat. Commun. 8, 1666 (2017).

43. Perea, D. E. et al. Determining the location and nearest neighbors of aluminium in zeolites with atom probe tomography. Nat. Commun. 6, 7589 (2015).

44. $\mathrm{Xu}, \mathrm{W}$. et al. A high-specific-strength and corrosion-resistant magnesium alloy. Nat. Mater. 14, 1229-1235 (2015).

45. Moutanabbir, O. et al. Colossal injection of catalyst atoms into silicon nanowires. Nature 496, 78-82 (2013).

46. Luo, Z. et al. Atomic gold-enabled three-dimensional lithography for silicon mesostructures. Science 348, 1451-1455 (2015).
47. Sun, Z. et al. Dopant diffusion and activation in silicon nanowires fabricated by ex situ doping: a correlative study via atom-probe tomography and scanning tunneling spectroscopy. Nano Lett. 16, 4490-4500 (2016).

48. Corma, A., Iborra, S. \& Velty, A. Chemical routes for the transformation of biomass into chemicals. Chem. Rev. 107, 2411-2502 (2007).

49. Wang, Z. et al. High population and dispersion of pentacoordinated AlV species on the surface of flame-made amorphous silica-alumina. Sci. Bull. 64, 516-523 (2019).

50. Wang, Z. et al. Palladium-doped silica-alumina catalysts obtained from double-flame FSP for chemoselective hydrogenation of the model aromatic ketone acetophenone. J. Catal. 302, 10-19 (2013).

51. Lang, S., Benz, M., Obenaus, U., Himmelmann, R. \& Hunger, M. Novel approach for the characterization of Lewis acidic solid catalysts by solid-state NMR spectroscopy. ChemCatChem 8, 2031-2036 (2016)

52. Wang, Z., Jiang, Y., Hunger, M., Baiker, A. \& Huang, J. Catalytic performance of Brønsted and Lewis acid sites in phenylglyoxal conversion on flame-derived silica-zirconia. ChemCatChem 6, 2970-2975 (2014).

53. Yin, F., Blumenfeld, A. L., Gruver, V. \& Fripiat, J. J. NH3 as a probe molecule for NMR and IR study of zeolite catalyst acidity. J. Phys. Chem. B 101, 1824-1830 (1997).

54. Ma, D. et al. An investigation of the roles of surface aluminum and acid sites in the zeolite MCM-22. Chem. Eur. J. 8, 162-170 (2002).

55. Zheng, A. M. et al. Relationship between H-1 chemical shifts of deuterated pyridinium ions and Brønsted acid strength of solid acids. J. Phys. Chem. B 111, 3085-3089 (2007).

56. De Geuser, F., Lefebvre, W. \& Blavette, D. 3D atom probe study of solute atoms clustering during natural ageing and pre-ageing of an Al-Mg-Si alloy. Philos. Mag. Lett. 86, 227-234 (2006)

57. Haley, D., Petersen, T., Barton, G. \& Ringer, S. P. Influence of field evaporation on Radial Distribution Functions in Atom Probe Tomography. Philos. Mag. 89, 925-943 (2009).

58. Stebbins, J. F. \& Xu, Z. NMR evidence for excess non-bridging oxygen in an aluminosilicate glass. Nature 390, 60-62 (1997).

59. Pauling, L. in The nature of the chemical bond: An introduction to modern structural chemistry. 3 ed. (Cornell University Press: Ithaca, NY, 1960).

60. Leydier, F. et al. Bronsted acidity of amorphous silica-alumina: The molecular rules of proton transfer. J. Catal. 284, 215-229 (2011).

61. Larmier, K. et al. Isopropanol dehydration on amorphous silica-alumina: synergy of Brønsted and Lewis acidities at pseudo-bridging silanols. Angew. Chem. Int. Ed. 56, 230-234 (2017).

62. Leydier, F., Chizallet, C., Costa, D. \& Raybaud, P. Revisiting carbenium chemistry on amorphous silica-alumina: Unraveling their milder acidity as compared to zeolites. J. Catal. 325, 35-47 (2015).

63. Ernst, H., Freude, D., Mildner, T., Pfeifer, H. High temperature 1 H MAS NMR studies of the proton mobility in zeolites. In Proceeding of the 12th International Zeolite Conference, Treacy, M. M. J., Marcus, B. K., Bisher, M. E., Higgins, J. B. Eds. (Materials Research Society: Warrendale), pp. 2955 (1999).

64. Goncalves, V. L. C., Rodrigues, R. C., Lorencato, R. \& Mota, C. J. A. Assessing the acid strength of solid acid catalysts with the use of linear free energy relationship: H/D exchange with substituted benzene derivatives. J. Catal. 248, 158-164 (2007).

65. Freude, D., Oehme, W., Schmiedel, H. \& Staudte, B. NMR-studies concerning Brønsted acidity of zeolites. J. Catal. 49, 123-134 (1977).

66. Felfer, P. et al. New approaches to nanoparticle sample fabrication for atom probe tomography. Ultramicroscopy 159, 413-419 (2015).

67. Mafra, L. et al. High-resolution $1 \mathrm{H}$ homonuclear dipolar recoupling NMR spectra of biological solids at MAS rates up to $67 \mathrm{kHz}$. J. Magn. Reson. 199, 111-114 (2009).

68. Siegel, R., Nakashima, T. T. \& Wasylishen, R. E. Signal enhancement of NMR spectra of half-integer quadrupolar nuclei in solids using hyperbolic secant pulses. Chem. Phys. Lett. 388, 441-445 (2004).

69. Madhu, P. K., Goldbourt, A., Frydman, L. \& Vega, S. Sensitivity enhancement of the MQMAS NMR experiment by fast amplitude modulation of the pulses. Chem. Phys. Lett. 307, 41-47 (1999).

70. Yao, Z., Kwak, H. T., Sakellariou, D., Emsley, L. \& Grandinetti, P. J. Sensitivity enhancement of the central transition NMR signal of quadrupolar nuclei under magic-angle spinning. Chem. Phys. Lett. 327, 85-90 (2000).

\section{Acknowledgements}

J.H. and Z.W. acknowledge the financial supports from Australian Research Council Discovery Projects (DP150103842, DP180104010, and DE190101618). J.H. thanks the University of Sydney SOAR fellowship, Sydney Nano Grand Challenge, and the International Project Development Funding. The authors acknowledge the kindly help from Prof. Michael Hunger at Stuttgart University for H/D exchange experiments during paper revision. O.L. J.L. and J.-P.A. are grateful for funding provided by the Region Nord/Pas de Calais (France), Europe (FEDER), CNRS, Ministère de l'Enseignement Supérieur et de la Recherche, CPER, Chevreul Institute (FR 2638), Infrastructure de Recherche en Résonance Magnétique 
Nucléaire à Très Haut Champ (IR-RMN, FR 3050), ENSCL, and contracts ANR-17-ERC20022 (EOS) and ANR-18-CE08-0015-01 (ThinGlass). This project has also received funding from the European Union's Horizon 2020 research and innovation program under grant agreement $n^{\circ} 731019$ (EUSMI). T.L. thanks Deutsche Forschungsgemeinsschaft (DFG) for financial support (project number 407513992) and Zentrumfür Grenzflächendominierte Höchstleistungswerkstoffe (ZGH) at Ruhr University Bochum for the access of infrastructure (FEI Helios G4 CX FIB/SEM and Cameca LEAP 5000 XR).

\section{Author contributions}

J.H., Y.J., and Z.W. designed the study. Y.J. and A.B. prepared the samples. Z.W., O.L., J.T., and J.H. performed the NMR experiments and structural assignation. T.L., and Z.L. performed the APT experiments. J.H. and J.-P.A. supervised the scientific work. J.H. and Z.W. contributed to writing the paper, and O.L., J.-P.A., A.B., and T.L. revised it.

\section{Competing interests}

The authors declare no competing interests.

\section{Additional information}

Supplementary information is available for this paper at https://doi.org/10.1038/s41467019-13907-7.

Correspondence and requests for materials should be addressed to J.-P.A. or J.H.
Peer review information Nature Communications thanks Bert Weckhuysen, and the other, anonymous, reviewer(s) for their contribution to the peer review of this work.

Reprints and permission information is available at http://www.nature.com/reprints

Publisher's note Springer Nature remains neutral with regard to jurisdictional claims in published maps and institutional affiliations.

\section{(c) (i)}

Open Access This article is licensed under a Creative Common Attribution 4.0 International License, which permits use, sharing, adaptation, distribution and reproduction in any medium or format, as long as you give appropriate credit to the original author(s) and the source, provide a link to the Creative Commons license, and indicate if changes were made. The images or other third party material in this article are included in the article's Creative Commons license, unless indicated otherwise in a credit line to the material. If material is not included in the article's Creative Commons license and your intended use is not permitted by statutory regulation or exceeds the permitted use, you will need to obtain permission directly from the copyright holder. To view a copy of this license, visit http://creativecommons.org/ licenses/by/4.0/.

(C) The Author(s) 2020 